October 2017

\title{
Frequency and outcome of acute neurologic complications after congenital heart disease surgery
}

Sidra Kaleem Jafri

Aga Khan University, sidra.kaleem@aku.edu

Lubaina Ehsan

Aga Khan University, m.eu@live.com

Qalab Abbas

Aga Khan University, qalab.abbas@aku.edu

Fatima Ali

Aga Khan University, fatima.ali@aku.edu

Prem Chand

Aga Khan University, prem.chand@aku.edu

See next page for additional authors

Follow this and additional works at: https://ecommons.aku.edu/ pakistan_fhs_mc_women_childhealth_paediatr

Part of the Pediatrics Commons

\section{Recommended Citation}

Jafri, S. K., Ehsan, L., Abbas, Q. Ali, F., Chand, P., Haque, A. (2017). Frequency and outcome of acute neurologic complications after congenital heart disease surgery. Journal of pediatric neurosciences, 12(4), 328-331.

Available at: https://ecommons.aku.edu/pakistan_fhs_mc_women_childhealth_paediatr/338 
Authors

Sidra Kaleem Jafri, Lubaina Ehsan, Qalab Abbas, Fatima Ali, Prem Chand, and Anwarul Haque 


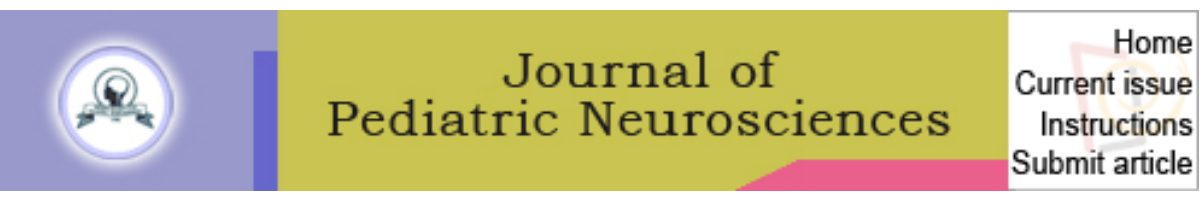

J Pediatr Neurosci. 2017 Oct-Dec; 12(4): 328-331.

PMCID: PMC5890551

doi: $\underline{10.4103 / j p n . J P N ~} 87 \quad 17$

PMID: $\underline{29675070}$

\title{
Frequency and Outcome of Acute Neurologic Complications after Congenital Heart Disease Surgery
}

\author{
Sidra Kaleem Jafri, Lubaina Ehsan, Qalab Abbas, Fatima Ali, Prem Chand, and Anwar UI Haque \\ Department of Pediatrics and Child Health, Aga Khan University Hospital, Karachi, Pakistan \\ Address for correspondence: Dr. Qalab Abbas, Department of Pediatrics and Child Health, Faculty Office Building, Aga Khan \\ University, Stadium Road, 74800 Karachi, Pakistan. E-mail: galababbas@gmail.com \\ Copyright : @ 2018 Journal of Pediatric Neurosciences
}

This is an open access article distributed under the terms of the Creative Commons Attribution-NonCommercial-ShareAlike 3.0 License, which allows others to remix, tweak, and build upon the work non-commercially, as long as the author is credited and the new creations are licensed under the identical terms.

Abstract Go to:

\section{Objectives:}

To determine the frequency and immediate outcome of acute neurologic complications (ANCs) in children undergoing congenital heart surgery (CHS).

\section{Materials and Methods:}

In this retrospective study, all patients undergoing CHS at our hospital from January 2007 to June 2016 were included. Patients were followed up for the development of seizures, altered level of consciousness (ALOC), abnormal movements, and stroke. Results are presented as mean with standard deviation and frequency with percentages.

\section{Results:}

Of 2000 patients who underwent CHS at our center during the study, 35 patients $(1.75 \%)$ developed ANC. Seizures occurred in $28(80 \%)$, ALOC in $5(14 \%)$, clinical stroke in 2, brain death in 6 patients. Antiepileptic drugs (AEDs) were started in 32 patients, of which 13 patients required more than one AED. Mean length of stay was $10 \pm 7.36$ days. Of 35 patients who developed ANC, 7 expired during the study.

\section{Conclusion:}

Neurological complications are scarce but significant morbidity after CHS at our center.

Keywords: Acute neurological complications, congenital heart surgery, outcome

\section{INTRODUCTION}

Go to:

Congenital heart defects (CHDs) are the most common types of birth defects accounting for $1 / 3^{\text {rd }}$ of the all major congenital defects.[1] Most of these defects require surgical correction in early childhood. With the increasing number of survivors after these complex surgeries, neurological abnormalities are increasingly being recognized.[2] The cardiopulmonary bypass (CPB) circuit has undergone 
tremendous growth and there is a robust implementation of neuroprotective strategies in the intraoperative and critical care. This has led to a decrease in the neurological morbidity.[3] The variability in outcome is not only related to procedural factors, but patient-specific factors have also been identified.[4] Several etiologies have been proposed including microembolization, hypoxia, hypoand hyper-perfusion, and biochemical disturbances that ultimately lead to neuronal damage.[2]

Previous studies have shown seizures to be the most common neurological complication in these patients with neurological injury occurring in $5 \%-25 \%$ of children undergoing open-heart surgery for congenital heart diseases.[프, $\underline{6}, \underline{7}]$ Other neurological symptoms include altered consciousness, abnormal muscle tone, hemiparesis, organic mental syndromes, dyskinesias, gaze palsies, and personality changes.[]

In developing countries like ours, data on immediate neurological outcome after repair are scarce, and in the absence of advanced technologies such as continuous electroencephalogram (EEG) and nearinfrared spectroscopy that is being routinely used, it cannot be picked early. The aim of this study was to determine the frequency of the neurological morbidities in our Pediatric Cardiac Intensive Care Unit and their outcome.

Medical records of all patients who underwent congenital heart surgery (CHS) at our hospital from January 2007 to June 2016 were searched to see patients who developed acute neurological complication after approval from the hospital's ethical review committee (4351-Ped-ERC-16). Our CHS program consists of 4 pediatric cardiologists, 1 congenital cardiac surgeon, 3 pediatric intensivists, and 3 pediatric cardiac anesthesiologists. Our Pediatric Cardiac Intensive Care Unit (PCICU) is a 4-bedded unit with round-the-clock physician coverage. Average $200 \mathrm{CHSs}$ are performed per year at our hospital. Majority of these are septal lesions and tetralogy of fallots. Neurological consultation by pediatric neurologist is available as and when needed. There is no facility of extracorporeal life support at our center. Data were also checked from log book of PCICU where robust data of all these patients are also maintained to avoid missing any data. All patients aged 1 day to 16 years who had undergone CHS with CPB were eligible for the study. This age was chosen as many patients present to us very late. The data were collected on a structured pro forma and included demographic information (age, gender, and so on), clinical variables including cardiac diagnosis, surgery type (on $\mathrm{CPB} /$ off $\mathrm{CPB}$ ), intraoperative data including the duration of CPB and aortic crossclamp time (in minutes), circulatory arrest, previous neurological problem, current neurologic problem (seizures, altered sensorium, abnormal movements, stroke), Glasgow coma scale (GCS), EEG findings, radiological investigations (computed tomography $[\mathrm{CT}] /$ magnetic resonance imaging $[\mathrm{MRI}]$ ), and serum electrolytes. Outcome variables included the patient being alive or expired on discharge, length of stay, and Glasgow coma outcome scale on discharge. Seizure was defined as either focal motor, generalized, or subtle (constituted by a sudden and paroxysmal increase in blood pressure, heart rate, or pupil size, unexplained by medication changes, pain, or hemodynamic modifications, in a paralyzed and intubated child whose movements would be impossible to observe).[ㄹ] EEG was not included in seizures definition as EEGs are done after clinical suspicion and almost all patients receive antiepileptic on clinical suspicion before the EEG is available. Abnormal movements were defined as any unwanted excess movement. This included chorea, athetosis, dystonia, and tremors.[]] Stroke was defined as either cell death in brain and spinal cord that is attributable to ischemia depending upon the pathological imaging or other objective evidence of cerebral or spinal cord ischemic injury in a defined vascular distribution. Also, clinical evidence of cerebral or spinal cord ischemic injury based on symptoms persisting $\geq 24$ h or until death, when other etiologies have been excluded.[]] GCS $<12$ was considered as altered level of consciousness (ALOC). Vasoactive inotropic score (VIS) was calculated as described by Gaies et al.[10] Data were entered and analyzed using Statistical Package for the Social 
Sciences (SPSS) version 20.0. Results are presented as frequencies with percentages and mean with standard deviation. Chi-square test was applied to determine the association of different factors with mortality.

RESULTS

Go to:

A total $35(1.75 \%)$ patients developed acute neurological complications among a total of 2000 patients who underwent CHS at our center. Median age of the participants was 19.5 months with interquartile range of 57 months while 67 (47/70) were males [Table 1]. Cyanotic congenital heart disease was present in 23 patients, 12 patients had single ventricle, and all patients had their surgery on CPB pump. Mean length of stay was $10 \pm 7.36$ days. Seven patients (20\%) who developed neurological morbidity expired during the study versus a total of 135 patients $(6.7 \%)$.

Table 1

Variables

Frequency (\%)

Age (median with IQR)

$18(42)$

Gender (male)

$25(71)$

Single ventricle

$12(34)$

Cyanotic heart disease

$23(65)$

Common cardiac lesions

Tetralogy of fallot

$12(34)$

Ventricular septal defect

Transposition of great arteries

5 (14)

Miscellaneous

$13(38)$

On cardiopulmonary bypass pump

$29(82)$

Length of stay

$12.46 \pm 8.354$

Outcome, (alive)

$28(80)$

\section{IQR: Interquartile range}

Basic demographic and clinical characteristics of the study subjects $(n=35)$

Among the neurological morbidity observed, seizures were observed in $28(80 \%), 5(14 \%)$ had ALOC, 2 patients had stroke, and $6(8.5 \%)$ patients developed brain death. EEG was done in 33/35 patients while CT scan brain was done in 10 patients which showed bleed in 2 cases and infarct in 2 other cases while MRI was done in another 10 patients which revealed infarct in 4 patients, bleed in 4 patients, and global ischemia in another 2 patients. Antiepileptic drugs (AEDs) were started in 32 patients and among these 13 patients required more than a single AED [Table 2]. 
Variable

Frequency (\%)

Clinical seizures

$28.2000(1.4)$

Altered level of consciousness

$5.2000(0.25)$

Abnormal movements

Stroke

$2.2000(0.1)$

Brain death

$6.2000(0.3)$

CT scan done

$10.2000(14.29)$

CT scan findings

Infarct

$2(2.86)$

Bleed

$2(2.86)$

MRI done

$10(14.29)$

MRI findings

Infarct

$4(5.71)$

Bleed

$2(2.86)$

Global ischemia

$2(2.86)$

Electroencephalography done

$33(94)$

Glasgow coma outcome scale mean $( \pm \mathrm{SD})$

$11.6( \pm 4.903)$

Antiepileptic drugs (AED) used

$32(90)$

Number of AEDs used

None

Single

$19(54)$

Multiple

$13(36)$

AED: Antiepileptic drugs, SD: Standard deviation, CT: Computed tomography, MRI: Magnetic resonance imaging

Open in a separate window

Spectrum and frequency of acute neurological complications in children who underwent congenital heart surgery

CPB time, VIS, and history of cardiopulmonary resuscitation during or after surgery were associated with death $(P<0.05)$.

The significance of neurological complications in corrective cardiac surgeries has been highlighted for many years.[11] In our study, the overall frequency of acute neurological complications was $1.75 \%$ 
with seizures being the most frequent complications with a frequency of $1.4 \%$ which is similar to that reported by Menache et al., but $<9 \%-32 \%$ reported by earlier retrospective series. $[\underline{3}, \underline{5}, \underline{12}]$ This shows that as the intraoperative techniques are improving, neurological complications are decreasing. EEG showed seizures in only four patients while other showed slow background activity, i.e., theta and delta waves. This is probably due to early suspicion, initiation, and aggressive control of seizure by of AED in these patients. The decision to do an EEG in our unit is done in accordance with consultation done with a pediatric neurologist who is available round the clock. Seizure control was achieved with single AED in $27 \%$ of our patients while Messinger et al. showed that $50 \%$ of their patients required single AED.[] $]$

We observed hemorrhagic and ischemic stroke in 2 patients each, 5 patients had ALOC, and 6 patients fulfilled brain death criteria. Out of these six patients, two patients had extensive intracerebral bleed in postoperative period and two patients had infarction on their radiological imaging. Infarct in these patients has been described to be due to micro- or macro-emboli as shown by Bellinger.[ㄹ, $\underline{13}]$ Bleeding in these patients postoperatively could be due to coagulopathy after CPB.

With the advancement of intraoperative techniques, risks of these complications have decreased considerably. We did not observe any abnormal movement probably as most of the patients were on sedative medications.

Our study has demonstrated that increasing CPB time and VIS are significantly associated with mortality in this patient cohort. Over the years, improvement in surgical outcomes has been observed due to improvement in $\mathrm{CPB}$ strategies. $\mathrm{CPB}$ causes a complex inflammatory response and alters many inflammatory biomarkers correlating with tissue damage.[14] The extended duration of circulatory arrest was found to be associated with increased risk of delayed psychomotor development and neurologic abnormalities at 1 year of life by Bellinger et al. Increased inotropic score was also identified as a risk factor in our study while Madhok et al. in their study showed that increased inotropic support led to elevated proinflammatory cytokines and decreasing the oxygen supply into the tissues thus increasing the morbidity.

In our study, a significant association was found between the length of stay and neurological complications highlighting the impact of these morbidities on resource utilization and outcome. In addition, seven patients died among cohort who developed neurological complication (20\%) against an overall mortality of $6.7 \%$ during the study.

Our study has the limitation of being a retrospective, single-center study with small sample size and we could not follow the patients who survived after hospital discharge for their long-term outcome.

Another limitation of our study is the less number of neonates and infants as we have not started neonatal cardiac surgery program yet. Nevertheless, we think it is a very comprehensive report on acute neurological from a developing country.

CONCLUSION Go to:

Perioperative neurological complications are scarce but a significant problem after CHS at our center. Studies on long-term outcome of these patients from our part of the world are needed.

Financial support and sponsorship

Nil.

\section{Conflicts of interest}

There are no conflicts of interest. 
1. van der Linde D, Konings EE, Slager MA, Witsenburg M, Helbing WA, Takkenberg JJ, et al. Birth prevalence of congenital heart disease worldwide: A systematic review and meta-analysis. J Am Coll Cardiol. 2011;58:2241-7. [PubMed]

2. Gaynor JW, Wernovsky G, Jarvik GP, Bernbaum J, Gerdes M, Zackai E, et al. Patient characteristics are important determinants of neurodevelopmental outcome at one year of age after neonatal and infant cardiac surgery. J Thorac Cardiovasc Surg. 2007;133:1344-53. 1353.e1-3. [PMC free article] [PubMed]

3. Menache CC, du Plessis AJ, Wessel DL, Jonas RA, Newburger JW. Current incidence of acute neurologic complications after open-heart operations in children. Ann Thorac Surg. 2002;73:1752-8. [PubMed]

4. Bird GL, Jeffries HE, Licht DJ, Wernovsky G, Weinberg PM, Pizarro C, et al. Neurological complications associated with the treatment of patients with congenital cardiac disease: Consensus definitions from the Multi-Societal Database Committee for Pediatric and Congenital Heart Disease. Cardiol Young. 2008;18(Supp1 2):234-9. [PMC free article] [PubMed]

5. Miller G, Eggli KD, Contant C, Baylen BG, Myers JL. Postoperative neurologic complications after open heart surgery on young infants. Arch Pediatr Adolesc Med. 1995;149:764-8. [ubMed]

6. Messinger MM, Dinh KL, McDade EJ, Moffett BS, Wilfong AA, Cabrera AG, et al. Outcomes in postoperative pediatric cardiac surgical patients who received an antiepileptic drug. J Pediatr

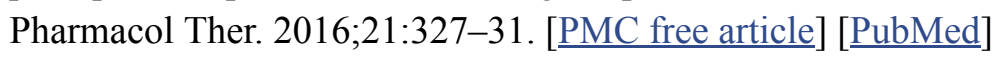

7. Fallon P, Aparício JM, Elliott MJ, Kirkham FJ. Incidence of neurological complications of surgery for congenital heart disease. Arch Dis Child. 1995;72:418-22. [MC free article] [ubMed]

8. Sanger TD, Chen D, Fehlings DL, Hallett M, Lang AE, Mink JW, et al. Definition and classification of hyperkinetic movements in childhood. Mov Disord. 2010;25:1538-49. [PMC free article] [PubMed]

9. Sacco RL, Kasner SE, Broderick JP, Caplan LR, Connors JJ, Culebras A, et al. An updated definition of stroke for the $21^{\text {st }}$ century: A statement for healthcare professionals from the American heart association/American stroke association. Stroke. 2013;44:2064-89. [PubMed]

10. Gaies MG, Gurney JG, Yen AH, Napoli ML, Gajarski RJ, Ohye RG, et al. Vasoactive-inotropic score as a predictor of morbidity and mortality in infants after cardiopulmonary bypass. Pediatr Crit Care Med. 2010;11:234-8. [ubMed]

11. Sakamoto T. Current status of brain protection during surgery for congenital cardiac defect. Gen Thorac Cardiovasc Surg. 2016;64:72-81. [PubMed]

12. Ferry PC. Neurologic sequelae of open-heart surgery in children. An 'irritating question' Am J Dis Child. 1990;144:369-73. [PubMed]

13. Bellinger DC, Wypij D, Kuban KC, Rappaport LA, Hickey PR, Wernovsky G, et al. Developmental and neurological status of children at 4 years of age after heart surgery with hypothermic circulatory arrest or low-flow cardiopulmonary bypass. Circulation. 1999;100:526-32. [PubMed]

14. Madhok AB, Ojamaa K, Haridas V, Parnell VA, Pahwa S, Chowdhury D, et al. Cytokine response in children undergoing surgery for congenital heart disease. Pediatr Cardiol. 2006;27:408-13.

[PubMed] 
Articles from Journal of Pediatric Neurosciences are provided here courtesy of Wolters Kluwer -- Medknow Publications 